\title{
Influence of Schottky contact on the C-V and J-V characteristics of HTM-free perovskite solar cells
}

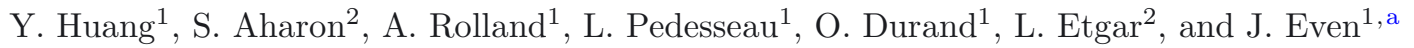 \\ 1 UMR FOTON CNRS 6082, INSA, 35708 Rennes, France \\ 2 Institute of Chemistry, Casali Center for Applied Chemistry, The Hebrew University of Jerusalem, Edmond J. Safra Campus, \\ Givat Ram, 91904 Jerusalem, Israel
}

Received: 30 September 2016 / Received in final form: 14 December 2016 / Accepted: 3 January 2017 (C) Y. Huang et al., published by EDP Sciences, 2017

\begin{abstract}
The influence of the Schottky contact is studied for hole transport material (HTM) free $\mathrm{CH}_{3} \mathrm{NH}_{3} \mathrm{PbI}_{3}$ perovskite solar cells (PSCs), by using drift-diffusion and small signal models. The basic current-voltage and capacitance-voltage characteristics are simulated in reasonable agreement with experimental data. The build in potential of the finite $\mathrm{CH}_{3} \mathrm{NH}_{3} \mathrm{PbI}_{3}$ layer is extracted from a Mott-Schottky capacitance analysis. Furthermore, hole collector conductors with work-functions of more than $5.5 \mathrm{eV}$ are proposed as solutions for high efficiency HTM-free $\mathrm{CH}_{3} \mathrm{NH}_{3} \mathrm{PbI}_{3}$ PSCs.
\end{abstract}

\section{Introduction}

Due to their potential for photo-induced carrier separation [1], various Hetero-Junction Solar Cells (HJSCs) have been experimentally $[2,3]$ and theoretically $[4,5]$ investigated Selected doped functional materials are added on each side of the Light Harvesting Material (LHM) to select photo-induced carriers. The electron transport material (ETM) is used to extract photo-induced electrons and block holes, while the hole transport material (HTM) has a complementary function. HJSCs based on low-cost, easy processed $[6-8]$ and highly absorbing $[9,10]$ semiconductor [11] halide perovskites have indeed led to high Photonto-electron Conversion Efficiency (PCE) rising from 3.8\% (2009) up to $22.1 \%$ (2016). Nowadays, these values are very close to the record value of silicon based solar cells $(25.6 \%)[12]$.

As predicted from the detailed balance principle [13], if no defect-assisted recombination occurs in LHM and if the cell open circuit voltage $\left(V_{O C}\right)$ equals to LHM's energy band gap $\left(E_{g}\right)$ divided by elemental electron charge $(q)$ the silicon based and the Perovskite based Solar Cells (PSC) should achieve maximum PCE of $44 \%$ and $37 \%$, respectively. However, due to limited Internal PL quantum yield (iQY) and non-zero entropy, the maximum $V_{O C}[14]$ is smaller than $E_{g}$ :

$$
q V_{O C}=E_{g}-T \Delta S-k_{B} T|\ln i Q Y|
$$

where $T$ is the absolute temperature and $k_{B}$ is the Boltzmann constant. If optical losses are weak and the

\footnotetext{
${ }^{a}$ e-mail: jacky.even@insa-rennes.fr
}

contacts are almost ideal, an open circuit voltage $\left(V_{O C}\right)$ of about $1.2 \mathrm{~V}$ is expected for $\mathrm{CH}_{3} \mathrm{NH}_{3} \mathrm{PbI}_{3}$ [15]. In pace with the enhancement of stability $[16,17]$, the influence of defects was weakened down to an acceptable level $[18,19]$, while the band offsets between the LHM and ETM or HTM remain major factors impeding PCE [15, 20-23]. $\mathrm{ZnO}$ nanorods [24] or PCBM [25], ETM [26] are able to minimize the band offset at the conduction band minimum (CBM) and allow building almost ideal contact at ETM/LHM interface. However HTM very often present large band offsets at valence band maximum (VBM) and low carrier mobility [23,27-29]. Alternatively, PSC without HTM layer was proposed as a solution towards high efficiency. After Etgar and coworkers early directly deposited gold on $\mathrm{CH}_{3} \mathrm{NH}_{3} \mathrm{PbI}_{3}$ and demonstrated that the $\mathrm{CH}_{3} \mathrm{NH}_{3} \mathrm{PbI}_{3}$ material can be simultaneously considered as a light harvester and a hole conductor, leading to PCE of $8 \%$ [30]. Then porous carbon film was used as contact for fully printable HTM-free PSCs with efficiency of $12.8 \%$ [17]. And PSCs with single-walled carbon nanotubes as hole collector achieved efficiency of $15 \%[31,32]$. In such case, solar cells benefit from fewer interfaces, and the optical and electrical losses in the HTM layer are eliminated as well. In Figure 1, the architecture of the HTM-free $\mathrm{CH}_{3} \mathrm{NH}_{3} \mathrm{PbI}_{3} \mathrm{PSC}$ is schematic represented by comparison to that of classical PSC Gold for example, is directly connected with $\mathrm{CH}_{3} \mathrm{NH}_{3} \mathrm{PbI}_{3}$ as the hole collection electrode and a Schottky contact is formed [33].

To get an insight into the HTM-free PSC operation, direct current and small signal simulation analyses [5,34-37] 


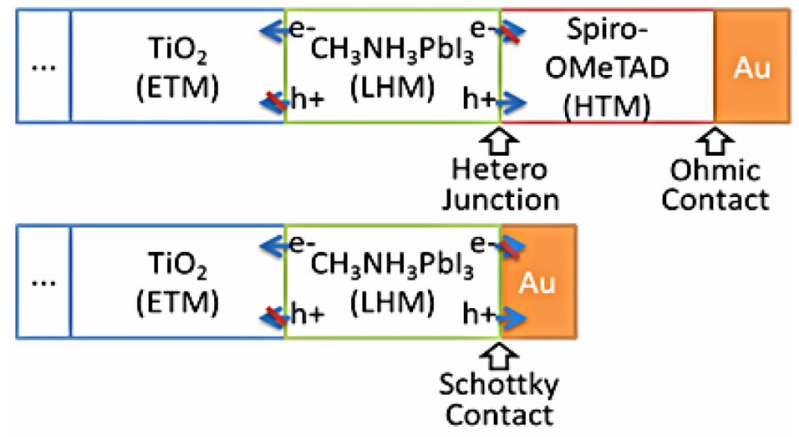

Fig. 1. Schematic representations of perovskite solar cells with (a) a hetero-junction or (b) a Schottky contact at hole collector side, respectively.

were performed including basic semiconductor models: the Poisson equation, the current continuity equation and a drift-diffusion model. The critical transport and recombination processes in solar cells can thus be quantitatively analyzed. Nevertheless, few numerical analyses were dedicated up to now to HTM-free PSCs. In our work, the basic current-voltage $(J-V)$ and capacitance-voltage $(C-V)$ characteristics of HTM-free $\mathrm{CH}_{3} \mathrm{NH}_{3} \mathrm{PbI}_{3}$ based PSCs are studied with drift-diffusion and small signal models [38], which are integrated in Silvaco Atlas simulator [39].

\section{Numerical modeling}

The physical model is numerically simulated in Atlas by solving a set of coupled equations including Poisson's equation (2), continuity (3a) and (3b) and transport equations (4a) and (4b) for electrons and holes densities. These equations link together the electrostatic potential profile and the charge distributions, and describe the evolution of electron and hole densities under external bias and light illumination, including carrier transport, generation, and recombination processes. The bimolecular recombination model corresponds to the formula (5). The trapassisted recombination model is described in formula (6), (7a) and (7b), while the photo-induced carrier generation processes are introduced through complex refractive index of materials. Simulations were carried out under equilibrium and small AC conditions, with and without AM1.5 sun illumination, in order to obtain $J-V$ and $C-V$ characteristics of HTM-free $\mathrm{CH}_{3} \mathrm{NH}_{3} \mathrm{PbI}_{3}$ PSCs

$$
\Delta \psi=-\frac{\rho}{\varepsilon}
$$

where $\psi$ is the potential, $\rho$ is the charge density and $\varepsilon$ is the dielectric constant.

$$
\begin{aligned}
& \frac{\partial n}{\partial t}=\frac{1}{q} \operatorname{div} \vec{J}_{n}+G_{n}-R_{n} \\
& \frac{\partial \mathrm{p}}{\partial t}=-\frac{1}{q} \operatorname{div} J_{p}+G_{p}-R_{p}
\end{aligned}
$$

where $n(p)$ is the electron (hole) density, $t$ is the time, $J_{n}$ $\left(J_{p}\right)$ is the electron (hole) current density, $G$ and $R$ are the generation and recombination rates respectively. The footnote $n(p)$ is related to electron (hole).

$$
\begin{gathered}
\overrightarrow{J_{n}}=-q \mu_{n} n \nabla \phi_{n} \\
\overrightarrow{J_{p}}=-q \mu_{p} p \nabla \phi_{p}
\end{gathered}
$$

where $\mu$ is mobility and $\phi$ is the quasi-Fermi level

$$
R_{b i}=k_{b i}\left(n p-n_{i}^{2}\right)
$$

where $k_{b i}$ is the bimolecular recombination coefficient and $n_{i}$ the intrinsic electron density

$$
\begin{gathered}
R_{S R H}=\frac{p n-n_{i}^{2}}{\tau_{n}\left[p+n_{i} \cdot \exp \left(\frac{-\Delta E}{k_{B} t}\right)\right]+\tau_{p}\left[n+n_{i} \cdot \exp \left(\frac{\Delta E}{k_{B} T}\right)\right]}(6) \\
\tau_{n}=\frac{1}{S I G_{n} \cdot v_{n} \cdot N_{t}} \\
\tau_{p}=\frac{1}{S I G_{p} \cdot v_{p} \cdot N_{t}} .
\end{gathered}
$$

The Shockley-Read-Hall (SRH) recombination mechanism is described by equation (6) $\tau$ is the charge carrier lifetime for trap-assisted process. The relationship between $\tau$ and trap density $\left(N_{t}\right)$ (Eq. (7)) depends on the traps capture cross section (SIG) and the thermal velocity $(v) . \Delta E$ is the absolute energy difference between the trap level and the intrinsic Fermi level $\left(E_{i}\right)$ in the bulk. $E_{i}$ is approximately located in the middle of energy band gap. If $\Delta E=0$, the maximum of SRH recombination rate is obtained. In other words, the deep trap centers lead to the highest recombination rates and are harmful for photo-induced carrier extraction. We set $\tau_{n}=\tau_{p}, \mu_{n}=\mu_{p}$ to reduce the number of parameters in the present work.

\section{Basic properties of HTM-free PSC}

A basic modeling of HTM-free Perovskite Solar Cells (PSCs) studied experimentally by Etgar's group [40], relies on $\mathrm{TiO}_{2} / \mathrm{CH}_{3} \mathrm{NH}_{3} \mathrm{PbI}_{3} / \mathrm{Au}$ architecture with a computed static band alignment shown in Figure 2. Heavily n-type doped ETM anatase $\left(\mathrm{TiO}_{2}\right)$ [41-43] and hole collector gold are added on each sides of lightly $\mathrm{n}$ or $\mathrm{p}$-doped $\mathrm{CH}_{3} \mathrm{NH}_{3} \mathrm{PbI}_{3}[1,44,45]$. Under thermal equilibrium and short circuit condition, the Fermi-level $\left(E_{f}\right)$ remains constant as reference through the device, and the band offsets at each interface yield two potential barriers. It is clear that the major potential drop $\Delta \psi$ is located in the $\mathrm{CH}_{3} \mathrm{NH}_{3} \mathrm{PbI}_{3}$ layer. Therefore, the major part of the electrical current originates from carrier drifting rather than carrier diffusion. The main properties of the materials used for the simulation are summarized in Table 1, including $\chi, E_{g}$, the doping level $(N)$, the effective masses of electron and hole $\left(m_{e}^{*} \& m_{h}^{*}\right)$ and the relative dielectric constant $\left(\varepsilon_{r}\right)$. The thickness of $\mathrm{TiO}_{2}$ and $\mathrm{CH}_{3} \mathrm{NH}_{3} \mathrm{PbI}_{3}$ layers are both equal to $300 \mathrm{~nm}$. The work function (WF) of gold is $5.1 \mathrm{eV}[33,46]$. An Ohmic contact is considered 
Table 1. Main properties of the materials.

\begin{tabular}{cccccc}
\hline & $\begin{array}{c}X \\
(\mathrm{eV})\end{array}$ & $\begin{array}{c}E_{g} \\
(\mathrm{eV})\end{array}$ & $\begin{array}{c}N \\
\left(\mathrm{~cm}^{-3}\right)\end{array}$ & $\begin{array}{c}m_{e}{ }^{*} \& m_{h}{ }^{*} \\
\left(\mathrm{~m}_{0}\right)\end{array}$ & $\begin{array}{c}\varepsilon_{r} \\
\left(\varepsilon_{0}\right)\end{array}$ \\
\hline \multirow{2}{*}{$\mathrm{HOIP}$} & 3.9 & \multirow{2}{*}{1.6} & $n=4 \mathrm{e} 16^{*}$ & $0.23 \& 0.29$ & 70 \\
& & & or $p=8 e 16^{*}$ & {$[48]$} & {$[49]$} \\
$\mathrm{TiO}_{2}$ & 4.1 & 3.3 & $1 \mathrm{e} 19[41]$ & $\begin{array}{c}5.6 \& 5.6 \\
{[50]}\end{array}$ & $\begin{array}{c}31 \\
{[51]}\end{array}$ \\
\hline
\end{tabular}

Notes: HOIP means $\mathrm{CH}_{3} \mathrm{NH}_{3} \mathrm{PbI}_{3} ; *$ indicates fitting parameter.

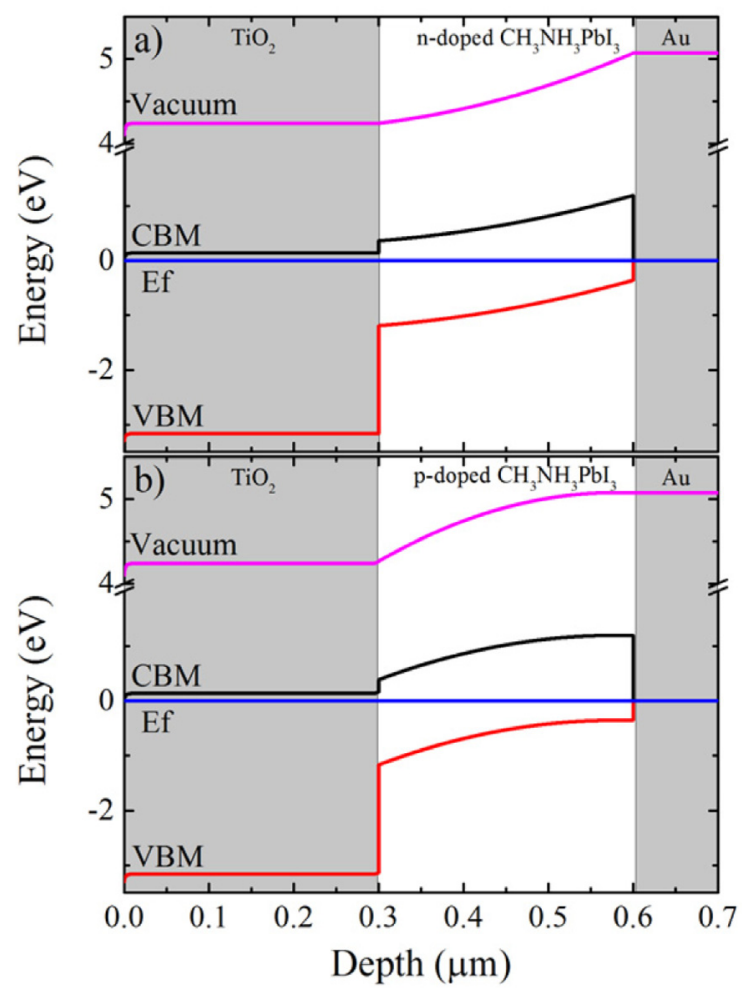

Fig. 2. Static band diagram of (a) n-doped and (b) p-doped $\mathrm{CH}_{3} \mathrm{NH}_{3} \mathrm{PbI}_{3}$ based HTM-free PSCs.

at the bottom of the $\mathrm{TiO}_{2}$ layer on the other side. The bimolecular recombination coefficient $k_{b i}$ of $\mathrm{CH}_{3} \mathrm{NH}_{3} \mathrm{PbI}_{3}$ is $10^{-9} \mathrm{~cm}^{3} / \mathrm{s}$ [47]. Due to lack of precise trap characterization, $\Delta E$ is set to zero and $N_{t}$ is $10^{10} \mathrm{~cm}^{-3}$, while $\tau$ and $\mu$ are tuned to match the experimental data.

\subsection{Capacitance characteristics}

In order to obtain efficient energy conversion in solar cells with low mobility LHM, a high build in potential $\left(V_{b i}\right)$ is necessary to prevent significant losses due to carrier recombination processes competing with charge extraction processes [52]. In our case, a Schottky contact [53] is formed at interface $\mathrm{CH}_{3} \mathrm{NH}_{3} \mathrm{PbI}_{3} / \mathrm{Au}$. Therefore, $V_{b i}$ can be extracted from a Mott-Schottky capacitance analysis. The device architecture in our work is shown together with the circuit in Figure 3. The capacitance expression

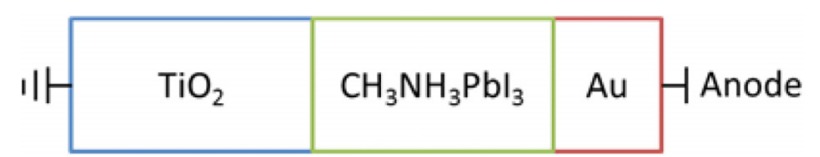

Fig. 3. Circuit used for Mott-Schottky capacitance analysis.

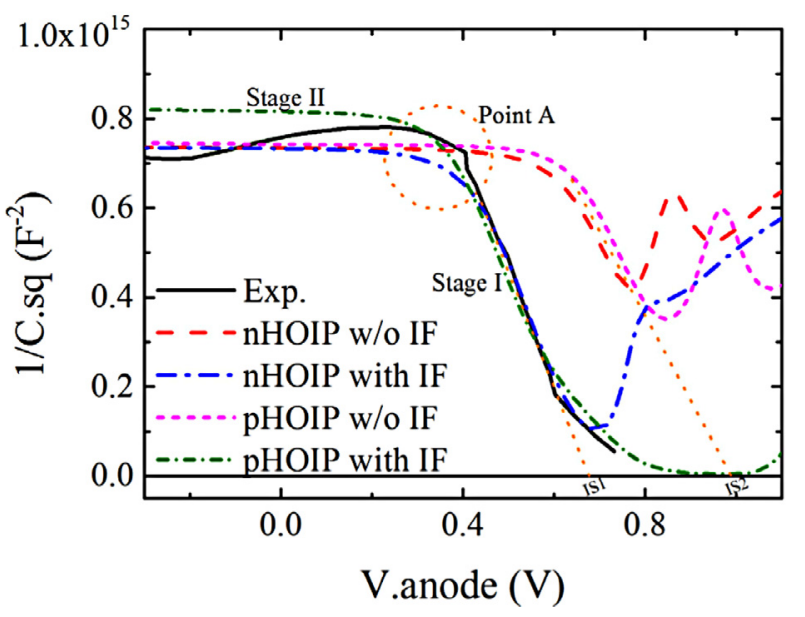

Fig. 4. The computed and experimental (solid line) $C-V$ characteristics in dark of HTM-free PSC. N-doped HOIP with (without) an n-doped interfacial layer (IF) at Au/HOIP interface is indicated as dash dot (dash) line. P-doped HOIP with (without) a p-doped IF at $\mathrm{TiO}_{2} / \mathrm{HOIP}$ interface is indicated as short dash dot (short dash) line. The $V_{b i}$ values extracted from the IS1 and IS2 intersections are equal to 0.6 and $0.9 \mathrm{~V}$, respectively.

is given by:

$$
\frac{1}{C^{2}}=\frac{2}{q A^{2} \varepsilon_{0}}\left(\frac{1}{N \varepsilon_{r}}\right)\left(V_{b i}-V_{b i a s}+\frac{k_{B} T}{q}\right)
$$

where $C$ is the junction capacitance, $A$ is the junction area, $\varepsilon$ is the vacuum permittivity, $N$ is the activated dopant density in semiconductor and $\varepsilon_{r}$ is the relative permittivity. In our work, a small signal analysis [38] is used to simulate $C-V$ characteristics of $\mathrm{HTM}$-free $\mathrm{CH}_{3} \mathrm{NH}_{3} \mathrm{PbI}_{3}$ PSC. The signal frequency is set at $1 \mathrm{kHz}$ for simulation, as in practical measurement. The theoretical characteristics is presented in Figure 4 and compared to available experimental data [40]. In order to fit the experimental data, an effective interfacial layer (IF) was introduced into the architecture for each type of $\mathrm{CH}_{3} \mathrm{NH}_{3} \mathrm{PbI}_{3}$. For ndoped $\mathrm{CH}_{3} \mathrm{NH}_{3} \mathrm{PbI}_{3}$, the IF of $8.5 \mathrm{~nm}$ is heavily n-doped and located between $\mathrm{Au}$ and $\mathrm{CH}_{3} \mathrm{NH}_{3} \mathrm{PbI}_{3}$. For p-doped $\mathrm{CH}_{3} \mathrm{NH}_{3} \mathrm{PbI}_{3}$, the IF of $3.4 \mathrm{~nm}$ is heavily p-doped and located between $\mathrm{TiO}_{2}$ and $\mathrm{CH}_{3} \mathrm{NH}_{3} \mathrm{PbI}_{3}$. The doping level of each IF is equal to $2 \mathrm{e} 19 \mathrm{~cm}^{-3}$. The influence of IF is further discussed at the end of the section.

As the bias reversely increases, the extension of the depletion region starts at the $\mathrm{CH}_{3} \mathrm{NH}_{3} \mathrm{PbI}_{3} / \mathrm{Au}$ interface, then goes through the $\mathrm{CH}_{3} \mathrm{NH}_{3} \mathrm{PbI}_{3}$ and finally into the $\mathrm{TiO}_{2}$ Because of the different $N$ and $\varepsilon_{r}$ values in both $\mathrm{CH}_{3} \mathrm{NH}_{3} \mathrm{PbI}_{3}$ and $\mathrm{TiO}_{2}, C-V$ curves under reverse bias are bent into two stages. Similar phenomena were observed 
for III-V semiconductors $[54,55]$. The roughly constant capacitance at stage II is due to the heavy doping level in $\mathrm{TiO}_{2}$, in comparison with the smaller slope related to the small doping level in $\mathrm{CH}_{3} \mathrm{NH}_{3} \mathrm{PbI}_{3}$. The point $\mathrm{A}$ in Figure 4 corresponds to the transition point of the depletion region from stage I to stage II. According to expression (8), the $V_{b i}$ of a finite $\mathrm{CH}_{3} \mathrm{NH}_{3} \mathrm{PbI}_{3}$ layer is extracted from the intersection (IS) as pointed out in Figure 4. The fluctuations of experimental data at stage II can be explained by non-uninform doping in the $\mathrm{TiO}_{2}$ layer. Because of the huge effective surface area of nano-porous $\mathrm{TiO}_{2}$ [56-58] and the rough surface of $\mathrm{CH}_{3} \mathrm{NH}_{3} \mathrm{PbI}_{3}$ layer [58], it is risky to extract $N, \varepsilon_{r}$ or thickness $(d)$ of $\mathrm{CH}_{3} \mathrm{NH}_{3} \mathrm{PbI}_{3}$ from the expression (8) and classic parallel plate capacitance expression (9), directly. In the model the effective area of capacitance interface $\left(A_{e f f}\right)$ is around two times as large as the active area of practical gold electrode

$$
C=\frac{\varepsilon_{r} \varepsilon_{0} A_{e f f}}{d}
$$

If more uniform growth of material layers for HTM-free PSCs is achieved in the future, it will be possible to extract more quantitative information from $C-V$ measurements, related to $N, \varepsilon_{r}$ and the thickness of the $\mathrm{CH}_{3} \mathrm{NH}_{3} \mathrm{PbI}_{3}$ layer.

\subsection{Photovoltaic characteristics}

Due probably to the different growth procedures employed by the experimental groups, some deviations are found for the absorption coefficients values of $\mathrm{CH}_{3} \mathrm{NH}_{3} \mathrm{PbI}_{3}$ in reference [59]. For that reason, the absorption coefficient curve used in our simulation was rather obtained by fitting the experimental IPCE spectrum data. In Figure 5 , the simulated $J$ - $V$ characteristics under 1 sun of 1.5 AM illumination are presented along with experimental data. A good matching to the experimental $J-V$ curve is achieved based on $n$-type $\mathrm{CH}_{3} \mathrm{NH}_{3} \mathrm{PbI}_{3}$ when its $\tau=80 \mathrm{~ns}$ and $\mu=0.2 \mathrm{~cm}^{2} / \mathrm{Vs}$. These empirical values are consistent with commonly measured values for the $\mathrm{CH}_{3} \mathrm{NH}_{3} \mathrm{PbI}_{3}$ material. The paper will only discuss n-doped $\mathrm{CH}_{3} \mathrm{NH}_{3} \mathrm{PbI}_{3}$ based PSCs in the following sections, because a better agreement with experimental $C-V$ and $J-V$ characteristics is obtained in this case

From the comparison of the experimental and computed $C-V$ characteristics (Fig. 4), it is necessary to assume that a heavily n-doped IF exists at the $\mathrm{CH}_{3} \mathrm{NH}_{3} \mathrm{PbI}_{3} / \mathrm{Au}$ contact. Alternative hypotheses with layers containing acceptors or surface states, were explored but without success. Indirect evidences of the existence of such an IF can be found in the report of Liu's group [33]. Using ultraviolet photoemission spectroscopy (UPS), these authors indeed showed that during the deposition of the gold contact, the Fermi level undergoes a progressive shift. Noteworthy, the presence of metal nano particles [60] or charged ions [61-63] at the interface was discussed by other groups. This Fermi level shift is simulated in the present work by introducing an effective and

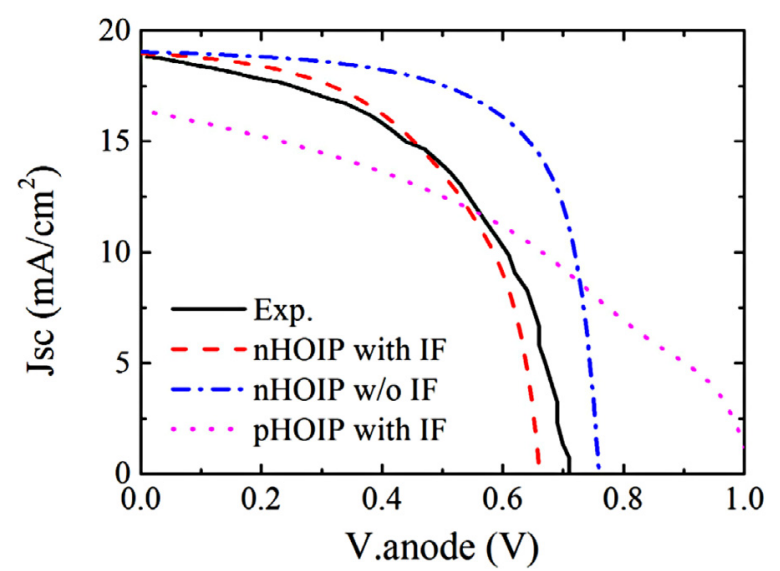

Fig. 5. $J-V$ characteristics under 1 sun illumination of n-doped $\mathrm{CH}_{3} \mathrm{NH}_{3} \mathrm{PbI}_{3}$ based HTM-free PSCs with (dash line) and without (dash dot line) interfacial layer (IF) The $\tau$ and $\mu$ of n-doped $\mathrm{CH}_{3} \mathrm{NH}_{3} \mathrm{PbI}_{3}$ are equals to $80 \mathrm{~ns}$ and $0.2 \mathrm{~cm}^{2} / \mathrm{Vs}$, respectively. And p-type $\mathrm{CH}_{3} \mathrm{NH}_{3} \mathrm{PbI}_{3}$ is pictured by dot line as example with $\tau$ of $18 \mathrm{~ns}$ and $\mu$ of $0.2 \mathrm{~cm}^{2} / \mathrm{Vs}$.

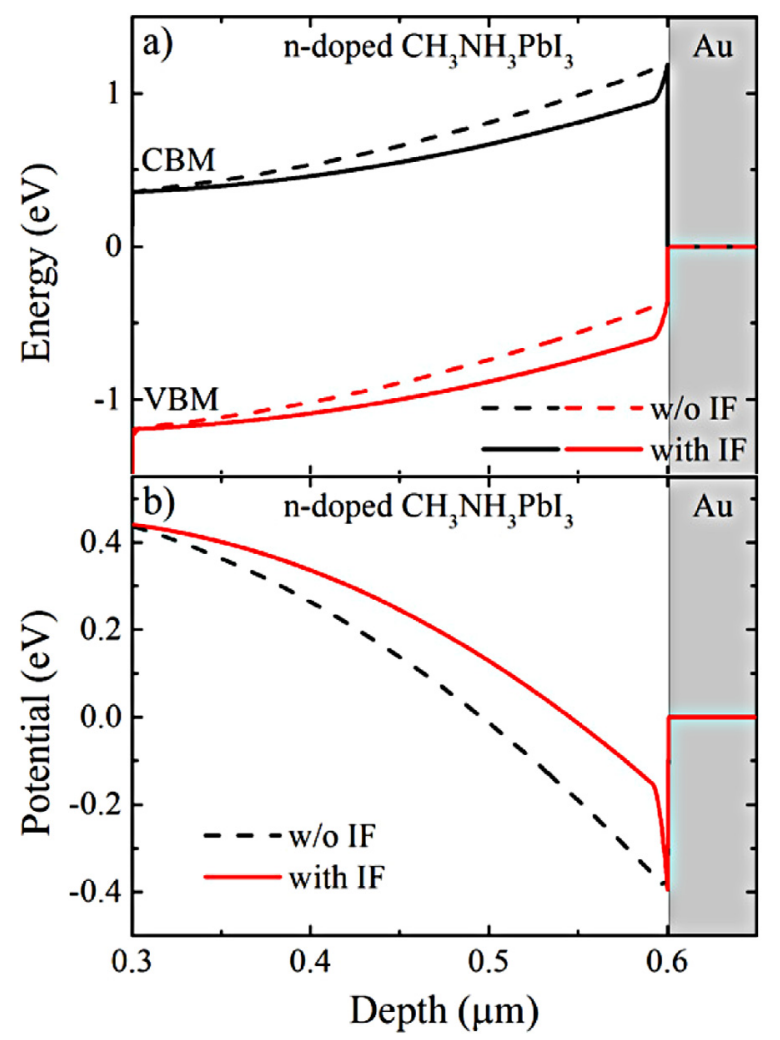

Fig. 6. (a) Static band alignment and (b) potential profile with and without interfacial layer (IF).

heavily n-doped $\mathrm{CH}_{3} \mathrm{NH}_{3} \mathrm{PbI}_{3} \mathrm{IF}$. The high density of positive ionized charges in the IF leads to a reduction of the $V_{b i}$ from 0.9 to $0.6 \mathrm{~V}$, in good agreement with the experimental value (Fig. 4).

The static band alignment and potential profile with and without IF are represented in Figures $6 \mathrm{a}$ and $6 \mathrm{~b}$, to have an insight into the device operation. Even though 

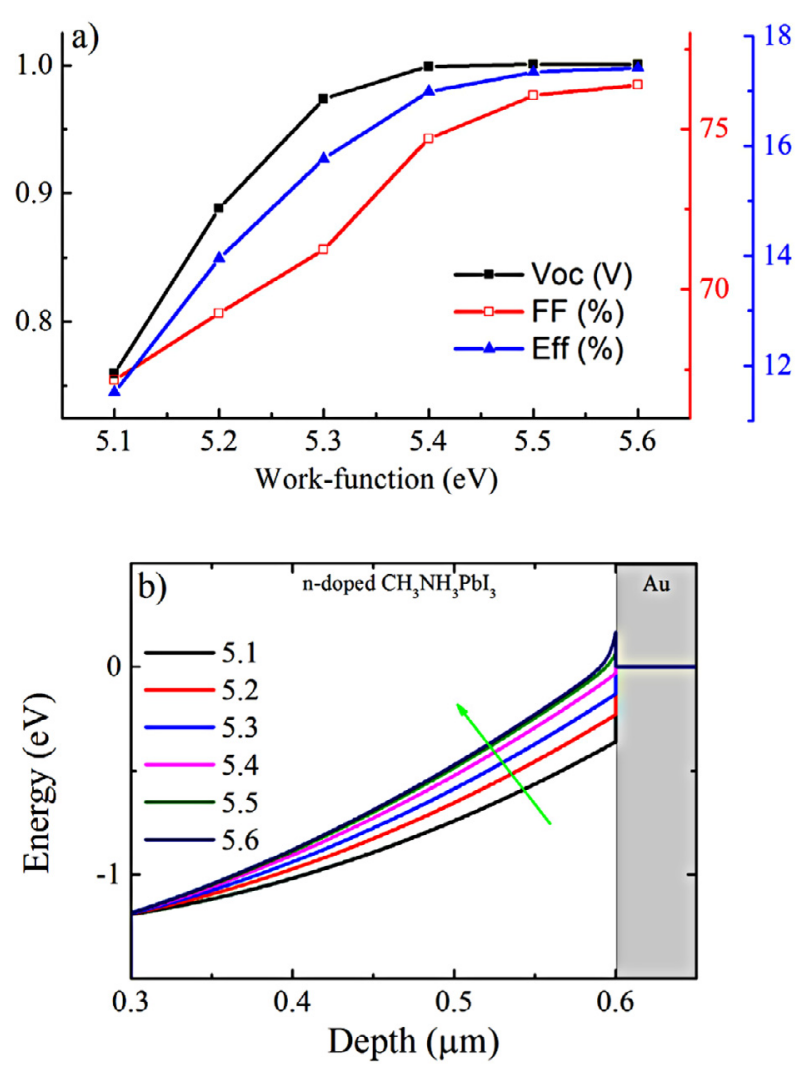

Fig. 7. (a) Open circuit voltage $\left(V_{O C}\right)$, fill factor $(\mathrm{FF})$ and efficiency (Eff) of HTM-free $\mathrm{CH}_{3} \mathrm{NH}_{3} \mathrm{PbI}_{3} \mathrm{PSC}$ as a function of the work-function (WF) of hole collector conductor. (b) Valence band variation as a function of WF.

the band offset at the $\mathrm{CH}_{3} \mathrm{NH}_{3} \mathrm{PbI}_{3}$ surface is pinned by the gold contact, the effective potential drop across the $\mathrm{CH}_{3} \mathrm{NH}_{3} \mathrm{PbI}_{3}$ layer is lowered by the presence of the IF. As a consequence, the losses due to carrier recombination processes increase and the efficiency of PSC decreases from $11 \%$ to $8 \%$, as shown in Figure 5 . A thick IF has clearly a detrimental effect on the photovoltaic efficiency.

\section{Influence of work-function}

The efficiencies of the PSC can be increased by improving the intrinsic properties of the perovskite ( $\tau$ and $\mu)$. We propose in this work to explore an additional possibility for HTM-free PSC. It is indeed possible to enlarge $V_{b i}$ by increasing the WF of the metal used for the Schottky contact. In Figure $7 \mathrm{a}, V_{O C}$, fill factor and efficiency are presented as a function of WF. These parameters are improved until saturation is reached for a WF value of $5.6 \mathrm{eV}$, while the short circuit current $\left(J_{S C}\right)$ is almost constant and equal to $19 \mathrm{~mA} / \mathrm{cm}^{2}$. The efficiency of HTM-free PSC can be enhanced up to $17 \%$ (Fig. 7a) by this way, and as stated before further enhancements could also be expected by improving the intrinsic properties of the perovskite.

Furthermore, as shown in Figure $7 \mathrm{~b}$, the change of $\mathrm{VBM}$ is very small except for the part close to the
$\mathrm{CH}_{3} \mathrm{NH}_{3} \mathrm{PbI}_{3} / \mathrm{Au}$ interface, as the WF of the metal increases up to $5.6 \mathrm{eV}$, larger than the $\mathrm{VBM}$ of $\mathrm{CH}_{3} \mathrm{NH}_{3} \mathrm{PbI}_{3}$ $(5.5 \mathrm{eV})$. As a result, the overall $V_{b i}$ in $\mathrm{CH}_{3} \mathrm{NH}_{3} \mathrm{PbI}_{3}$ layer becomes almost saturated. When the carrier recombination rate is small enough, the $J_{S C}$ mainly depends on absorption properties and is almost independent of $V_{b i}$. Palladium [46,64] or Selenium [65] are examples of hole collector conductors with WF larger than $5.5 \mathrm{eV}$.

\section{Conclusion}

In summary, a detailed investigation of $C-V$ and $J-V$ characteristics of HTM-free $\mathrm{CH}_{3} \mathrm{NH}_{3} \mathrm{PbI}_{3}$ PSC has been proposed, based on the drift-diffusion model and small signal analysis. The simulation results are in good agreement with experimental data. An effective heavily doped interfacial layer was introduced at the interface to fit the $C-V$ characteristics It is also shown in this work that, an increase of WF of the hole collector conductor, is expected to enhance the PSC efficiency.

The work at FOTON was supported by French ANR SupersansPlomb project.

\section{References}

1. C.-S. Jiang et al., Nat. Commun. 6, 8397 (2015)

2. M. Grätzel, J. Photochem. Photobiol. C Photochem. Rev. 4, $145(2003)$

3. W. Zhang, G.E. Eperon, H.J. Snaith, Nat. Energy 2016, 16048 (2016)

4. Q. Wang et al., J. Phys. Chem. B 110, 25210 (2006)

5. J. Bisquert, L. Bertoluzzi, I. Mora-Sero, G. GarciaBelmonte, J. Phys. Chem. C 118, 18983 (2014)

6. W. Nie et al., Science 347, 522 (2015)

7. M.M. Lee, J. Teuscher, T. Miyasaka, T.N. Murakami, H.J. Snaith, Science 338, 643 (2012)

8. J. Burschka et al., Nature 499, 316 (2013)

9. J. Even, L. Pedesseau, J.-M. Jancu, C. Katan, J. Phys. Chem. Lett. 4, 2999 (2013)

10. J.M. Ball et al., Energy Env. Sci 8, 602 (2015)

11. J. Even et al., J. Phys. Chem. C 119, 10161 (2015)

12. NREL Efficiency Chart Rev. (2016) Available at: http:// www.nrel.gov/ncpv/images/efficiency_chart.jpg

13. W. Shockley, H.J. Queisser, J. Appl. Phys. 32, 510 (1961)

14. C.M. Sutter-Fella et al., Nano Lett. 16, 800 (2016)

15. P. Gao, M. Grätzel, M.K. Nazeeruddin, Energy Environ. Sci. 7, 2448 (2014)

16. W. Nie et al., Nat. Commun. 7, 11574 (2016)

17. A. Mei et al., Science 345, 295 (2014)

18. W. Qiu et al., Energy Env. Sci 9, 484 (2016)

19. T.M. Brenner, D.A. Egger, L. Kronik, G. Hodes, D. Cahen, Nat. Rev. Mater. 1, 15007 (2016)

20. T. Minemoto, M. Murata, Sol. Energy Mater. Sol. Cells 133, $8(2015)$

21. E.J. Juarez-Perez et al., J. Phys. Chem. Lett. 5, 680 (2014)

22. W. Li et al., Energy Env. Sci. 9, 490 (2016)

23. P. Schulz et al., Energy Environ. Sci. 7, 1377 (2014) 
24. J. Dong, J. Shi, D. Li, Y. Luo, Q. Meng, Appl. Phys. Lett. 107, 073507 (2015)

25. O. Malinkiewicz et al., Nat. Photonics 8, 128 (2014)

26. K.-W. Tsai, C.-C. Chueh, S.T. Williams, T.-C. Wen, A.K.Y. Jen, J. Mater. Chem. A 3, 9128 (2015)

27. M. Saliba et al., Nat. Energy 1, 15017 (2016)

28. C. Chappaz-Gillot et al., Sol. Energy Mater. Sol. Cells 120, $163(2014)$

29. W. Chen et al., Science 350, 944 (2015)

30. L. Etgar et al., J. Am. Chem. Soc. 134, 17396 (2012)

31. S.N. Habisreutinger et al., J. Phys. Chem. Lett. 5, 4207 (2014)

32. K. Aitola et al., Energy Env. Sci. 9, 461 (2016)

33. X. Liu et al., Phys. Chem. Chem. Phys. 17, 896 (2014)

34. V. Gonzalez-Pedro et al., Nano Lett. 14, 888 (2014)

35. Y.T. Set, B. Li, F.J. Lim, E. Birgersson, J. Luther, Appl. Phys. Lett. 107, 173301 (2015)

36. X. Sun, R. Asadpour, W. Nie, A.D. Mohite, M.A. Alam, IEEE J. Photovolt. 5, 1389 (2015)

37. Y.T. Set, E. Birgersson, J. Luther, Phys. Rev. Appl. 5, $054002(2016)$

38. S.E. Laux, IEEE Trans. Electron Devices 32, 2028 (1985)

39. Silvaco Inc., ATLAS user's manual (2012), http://silvaco. com

40. W.A. Laban, L. Etgar, Energy Environ. Sci. 6, 3249 (2013)

41. G. Liu, W. Jaegermann, J. He, V. Sundström, L. Sun, J. Phys. Chem. B 106, 5814 (2002)

42. H. Tang, K. Prasad, R. Sanjinès, P.E. Schmid, F. Lévy, J. Appl. Phys. 75, 2042 (1994)

43. L. Forro et al., J. Appl. Phys. 75, 633 (1994)

44. E.M. Miller et al., Phys. Chem. Chem. Phys. 16, 22122 (2014)
45. Q. Wang et al., Appl. Phys. Lett. 105, 163508 (2014)

46. H.B. Michaelson, J. Appl. Phys. 48, 4729 (1977)

47. A. Paulke et al., Appl. Phys. Lett. 108, 113505 (2016)

48. G. Giorgi, J.-I. Fujisawa, H. Segawa, K. Yamashita, J. Phys. Chem. Lett. 4, 4213 (2013)

49. Q. Lin, A. Armin, R.C.R. Nagiri, P.L. Burn, P. Meredith, Nat. Photon. 9, 106 (2014)

50. S. Rühle, D. Cahen, J. Phys. Chem. B 108, 17946 (2004)

51. S. Roberts, Phys. Rev. 76, 1215 (1949)

52. A. Pivrikas et al., Phys. Rev. Lett. 94, 176806 (2005)

53. C. Wang et al., J. Vac. Sci. Technol. B 33, 032401 (2015)

54. A. Morii, H. Okagawa, K. Hara, J. Yoshino, H. Kukimoto, Jpn J. Appl. Phys. 31, L1161 (1992)

55. H. Kroemer, W.-Y. Chien, J.S.H. Jr., D.D. Edwall, Appl. Phys. Lett. 36, 295 (1980)

56. S. Nakade et al., Electrochem. Commun. 5, 804 (2003)

57. P.M. Sommeling et al., J. Phys. Chem. B 110, 19191 (2006)

58. S. Gamliel, A. Dymshits, S. Aharon, E. Terkieltaub, L. Etgar, J. Phys. Chem. C 119, 19722 (2015)

59. N.-G. Park, Nano Converg. 3, 1 (2016)

60. W. Zhang et al., Nano Lett. 13, 4505 (2013)

61. Y. Yuan et al., Adv. Energy Mater. 6, 1501803 (2016)

62. J.S. Yun et al., Adv. Energy Mater. 6, 1600330 (2016)

63. H. Yu, H. Lu, F. Xie, S. Zhou, N. Zhao, Adv. Funct. Mater. 26, 1411 (2016)

64. L. Baojun, L. Enke, Z. Fujia, Solid-State Electron. 41, 917 (1997)

65. A.M. Patil, V.S. Kumbhar, N.R. Chodankar, A.C. Lokhande, C.D. Lokhande, J. Colloid Interface Sci. 469, 257 (2016) 